\title{
Empirical Research on Pedagogical Dictionary Use in Recent 30 Years
}

\author{
Qian $\mathrm{Li}^{1}$ \\ ${ }^{1}$ Guangdong University of Foreign Studies, Guangdong, China \\ Correspondence: Qian Li, Guangdong University of Foreign Studies, Guangdong, China. \\ lqchristina@gdufs.edu.cn \\ Received: September 18, 2019 Accepted: October 12, 2019 Online Published: October 26, 2019 \\ doi:10.5539/jel.v8n6p103 URL: https://doi.org/10.5539/jel.v8n6p103
}

\begin{abstract}
Research on dictionary use is a relatively new field in lexicography. Among them, the empirical studies which were few before 1990s has gained ground over recent three decades. Using data of 35 articles from International Journal of Lexicography (1987-2017), this study renders an analysis of the empirical research trends in the field of dictionary use. The analysis mainly focuses on the research topics, research methodology, and the changes that have occurred in the field. The results show that while some hot topics (e.g., the effectiveness of dictionary use or of certain dictionary information) have remained popular over the past two decades, some topics, e.g., the exploration of dictionary using process have received an increasing attention, but some others, e.g., the investigation on habits and needs of dictionary use, have witnessed a decrease of interest recently. Furthermore, researchers have improved the methodological standards for recent studies. As for data analysis, more complicated statistic approaches, rather than pure descriptive statistics, have been adopted. Finally, based on the analysis on previous studies, this paper offers suggestions for further research trend.
\end{abstract}

Keywords: dictionary use research, research trend, research focus

\section{Introduction}

Before the 1980s, there were fewer dictionary use studies as compared to those on dictionary itself. Early in the 1980s, Hartman (1983) argued for more research of dictionary look-up behaviors for a full understanding of dictionary use. Ten years later, Béjoint (1994) pointed out that until 1990s, none of the general books of lexicography published had been concerned about users' behavior or habits in dictionary use.

In the 1980s and 1990s, the well-known "big four" (Oxford advanced learners' dictionary, Longman dictionary of contemporary English, the COBUILD English dictionary and the Cambridge international dictionary of English) launched a competition in the EFL dictionary market (Nesi, 2014). Since then, a substantial body of research have probed into dictionary use from a variety of perspectives, specifically on topics like comparisons among monolingual or bilingualised dictionaries (Atkins \& Varantola, 1997), effectiveness of paper versus electronic dictionaries (Nesi, 2000; Lew, 2016), and usefulness of a certain type of dictionary information (e.g., meaning, grammar information, or example sentences) for second language learning (Dziemianko, 2010; Nurmukhamedov, 2017). In addition to those topics, the recent decade also witnessed the occurrence of a new focus in this field - the exploration of dictionary use process in language learning (Lew et al., 2018). The development of dictionary use research, in some degree, accords with the advancement of general dictionary research, and also reflects the progress which other disciplines, such as psychology, cognitive science, second language acquisition etc, have achieved.

In brief, dictionary use research, carrying out from a variety of perspectives, constitutes one of the significant elements in the current lexicography research.

Previous studies concerning dictionary use can be categorized into different groups. Hartmann (1987) distinguished four types of dictionary use studies by means of their different research focuses, namely on the dictionary information categories; on specific dictionary user group; on the contexts of dictionary use; and on dictionary look-up strategies. McCreary and Dolezal (1999) classified the studies into five groups according to the research methods - experiential studies, comparative studies, users' needs and skills surveys, extra-lexicographical factors, and experimental studies. Nesi (2000) grouped the dictionary use research in accordance with data collection method: the use of questionnaires, the use of tests, and observation, and she analyzed the features and defects of those collection methods in her book. 
Recent research in lexicography is more concerned with the dictionary use research than ever before. In 2011, a special issue of the International Journal of Lexicography has devoted itself in full to the empirical study of dictionary use. In addition, within the recent 5 years, more articles concerning dictionary use appear in international top journals. This article tends to render an analysis of the empirical research on dictionary use so as to explore the research features and development tendency in this field.

The research questions are:

a. What is the current state of dictionary use in lexicography in terms of research focuses, data collection methods and data analysis methods?

b. What will be the development tendency for future dictionary use research?

\section{Current State of Dictionary Use}

The present study aims to investigate the features of previous studies on dictionary use which were published in International Journal of Lexicography (IJL) during the past thirty years (1988-2017). Among the 402 research articles published in this period, there were 43 articles concerning dictionary use, and 35 articles among them were empirical studies. The distribution of IJL articles on dictionary use since its first publication is presented in Table 1.

Table 1. IJL's publication about dictionary use research (1988-2017)

\begin{tabular}{llll}
\hline & Empirical & Overview & Total \\
\hline $1988-1996$ & $0(0 \%)$ & $1(2.3 \%)$ & $1(2.3 \%)$ \\
$1997-2006$ & $9(20.9 \%)$ & $2(4.6 \%)$ & $11(25.5 \%)$ \\
$2007-2017$ & $26(60.5 \%)$ & $5(11.6 \%)$ & $31(72.1 \%)$ \\
Total & $35(81.4 \%)$ & $8(18.6 \%)$ & $43(100 \%)$ \\
\hline
\end{tabular}

It can be seen that first, in the early stage when IJL was published (1988-1996), there were extremely few studies focusing on dictionary use, and no empirical study in this filed was published in IJL during that period. The interests on dictionary use rose on the second stage (1997-2006). There were altogether 11 studies (25.5\%) in this decade focusing on dictionary use, and most of the studies were empirical or experimental. In the third stage (2007-2017), the number of dictionary use studies has risen to 31 (72.1\%), and 26 studies among them were empirical studies. Figure 1 shows the different research types in different stages over the last thirty years.

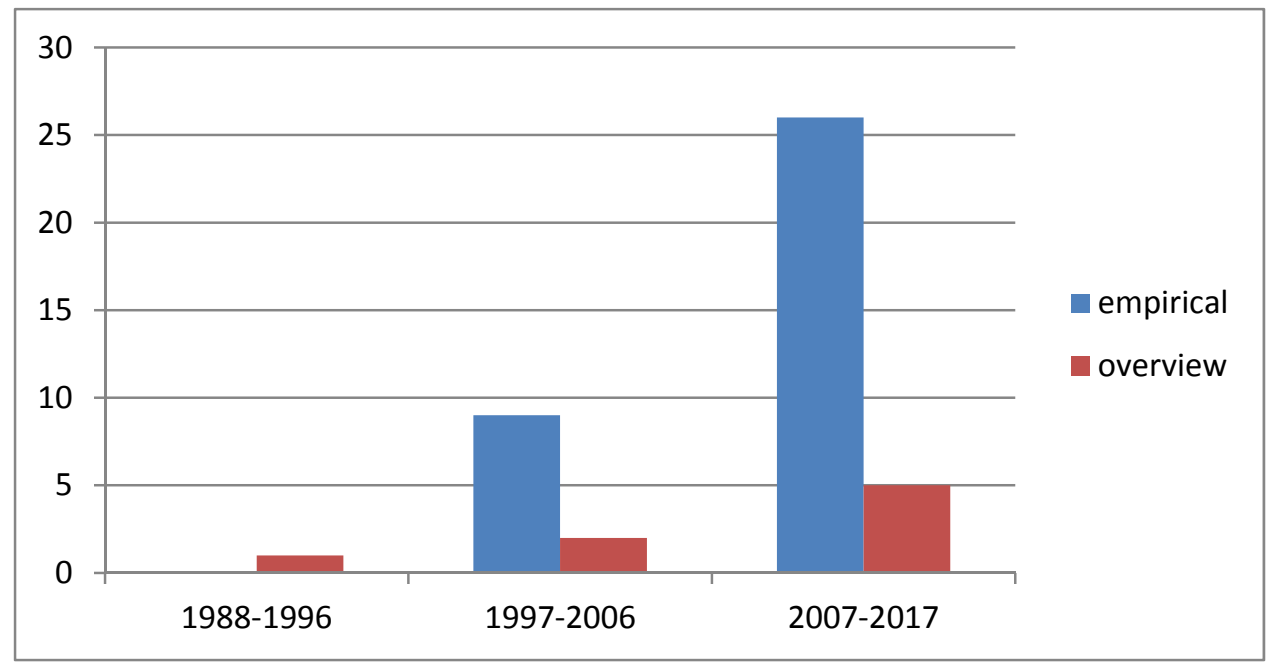

Figure 1. Research types in three stages

This figure reveals the general trend of the increasing interests on dictionary use in lexicography over the recent thirty years. More specifically, most of the existing dictionary use research adopted the empirical or experimental paradigm, in which the results and conclusions tend to be more valid and scientifically convincing. 
In the following sections, we are going to focus on different aspects of the existing dictionary use research so as to explore its development features over the recent thirty years.

\subsection{Change of Research Focus}

There were no empirical studies published in IJL in the period of 1988-1996. Most of dictionary use overviews published at that time were about expert opinion, intuition, or purely deductive reasoning. From the year of 1997 to the year of 2017, with the emergence of empirical studies, researchers mainly focused on the following five categories, namely, strategies or habits of dictionary use; effectiveness of dictionary use; selection or preference of dictionaries; dictionary using process; dictionary needs. Table 1 shows the distribution of different research focuses. Since it is from the year of 1997 that the empirical studies in dictionary use started, this section focuses on the research period from 1997 to 2017.

Table 2. Different research focuses

\begin{tabular}{llllll}
\hline & $\begin{array}{l}\text { Strategies or habits } \\
\text { of dictionary use }\end{array}$ & $\begin{array}{l}\text { Effectiveness of } \\
\text { dictionary use }\end{array}$ & $\begin{array}{l}\text { Selection or preference of } \\
\text { dictionaries }\end{array}$ & $\begin{array}{l}\text { Dictionary using } \\
\text { process }\end{array}$ & $\begin{array}{l}\text { Dictionary } \\
\text { needs }\end{array}$ \\
\hline $1997-2006$ & $4(11.4 \%)$ & $3(8.6 \%)$ & $1(2.9 \%)$ & $0(0 \%)$ & $2(5.7 \%)$ \\
$2007-2017$ & $1(2.9 \%)$ & $20(57.1 \%)$ & $2(5.7 \%)$ & $2(5.7 \%)$ & $0(0 \%)$ \\
Total & $5(14.3 \%)$ & $23(65.7 \%)$ & $3(8.6 \%)$ & $2(5.7 \%)$ & $2(5.7 \%)$ \\
\hline
\end{tabular}

It can be seen that in the period of 1997-2006, researchers paid much of their attention to the strategies or habits of dictionary use. They explored how dictionary users consulted dictionaries at a more indirect level, specifically which strategies and were used in the consultation process. For this type of research, questionnaires were used in most studies. In a more recent period (2007-2017), most of the attention was paid to the effectiveness of dictionary use, and the comparison was among the effectiveness of different types of dictionaries, or the effectiveness of dictionary use in a variety of learning tasks. In this period, some researchers placed the dictionary use research in a specific learning context, and treated "dictionary use" as a supplementary component in language learning process. Furthermore, dictionary using processes were explored by means of psychological methods, such as the eye-tracking and think-aloud methods. As compared with the period of 1997-2006, the most recent period saw more studies exploring how users consulted dictionaries by means of more direct ways.

\subsection{Methods for Data Collection}

Wiegand (1998, p. 569) identified four main types of data investigation techniques for user research: observation, written surveys, experiment/test, and content analysis of interviews. He also argued that these four methods can and should be combined in a variety of ways. The same classification was reiterated more recently by Nesi (2014), who further asserted a combination of surveys, observations, and tests to be clearly beneficial in dictionary research. In their work, He and Zhang (2009) provided a summary of the previous methods for data collection in dictionary use (He \& Zhang, 2009):

a. observation: to observe other users or themselves;

b. Interview: structured (choice of answers \& question order are fixed) or semi-structured;

c. Think-aloud: to ask users to report what he is thinking while using the dictionaries;

d. Questionnaire survey: to ask users to answer the questions in the questionnaire;

e. Test: not a strictly controlled study; to ask users to use dictionaries for a task and report the use;

f. Experiment: controlled studies with independent and dependent variables.

According to the degree of being direct in data collection, the methods for data collection can be listed in the following scale (He \& Zhang, 2009):

observation questionnaire interview think-aloud test experiment

(indirect, less controlled)

(direct, controlled)

Table 3 and Figure 2 show the distribution of different data collection methods. In the period of 1997-2006, among all the studies, the following three methods were used most frequently, namely self-report (27\%), questionnaire (18\%) and experiment (36\%). However, in a more recent period (2007-2017), most of the empirical studies adopted the way of doing an experiment (61.5\%) for dictionary use research, and some studies 
used test (11.4\%) for data collection. self-report and questionnaire were adopted by fewer studies in 1997-2007 than those in the period of 1997-2006. In addition, certain studies in 2007-2017 started to adopt interview (7.6\%) and think-aloud (7.6\%) to collect data. It was revealed that most of the recent studies were concerned with more direct and controlled methods in the dictionary use research.

Table 3. Distribution of data collection methods

\begin{tabular}{|c|c|c|c|c|c|c|c|c|}
\hline Period & Methods & & & & & & & \\
\hline & $\begin{array}{l}\text { Observation } \\
(\%)\end{array}$ & $\begin{array}{l}\text { interview } \\
(\%)\end{array}$ & $\begin{array}{l}\text { self-report } \\
(\%)\end{array}$ & $\begin{array}{l}\text { think-aloud } \\
(\%)\end{array}$ & $\begin{array}{l}\text { questionnaire } \\
(\%)\end{array}$ & $\begin{array}{l}\text { test } \\
(\%)\end{array}$ & $\begin{array}{l}\text { experiment } \\
(\%)\end{array}$ & Total \\
\hline 1997-2006 & $1(9 \%)$ & $0(0 \%)$ & $3(27 \%)$ & $0(0 \%)$ & $2(18 \%)$ & $1(9 \%)$ & $4(36 \%)$ & $16(100 \%)$ \\
\hline $2007-2017$ & $1(3.8 \%)$ & $2(7.6 \%)$ & $1(3.8 \%)$ & $2(7.6 \%)$ & $1(3.8 \%)$ & $3(11.4 \%)$ & $16(61.5 \%)$ & $26(100 \%)$ \\
\hline
\end{tabular}

The following figure shows the comparison of data collection methods in different periods.

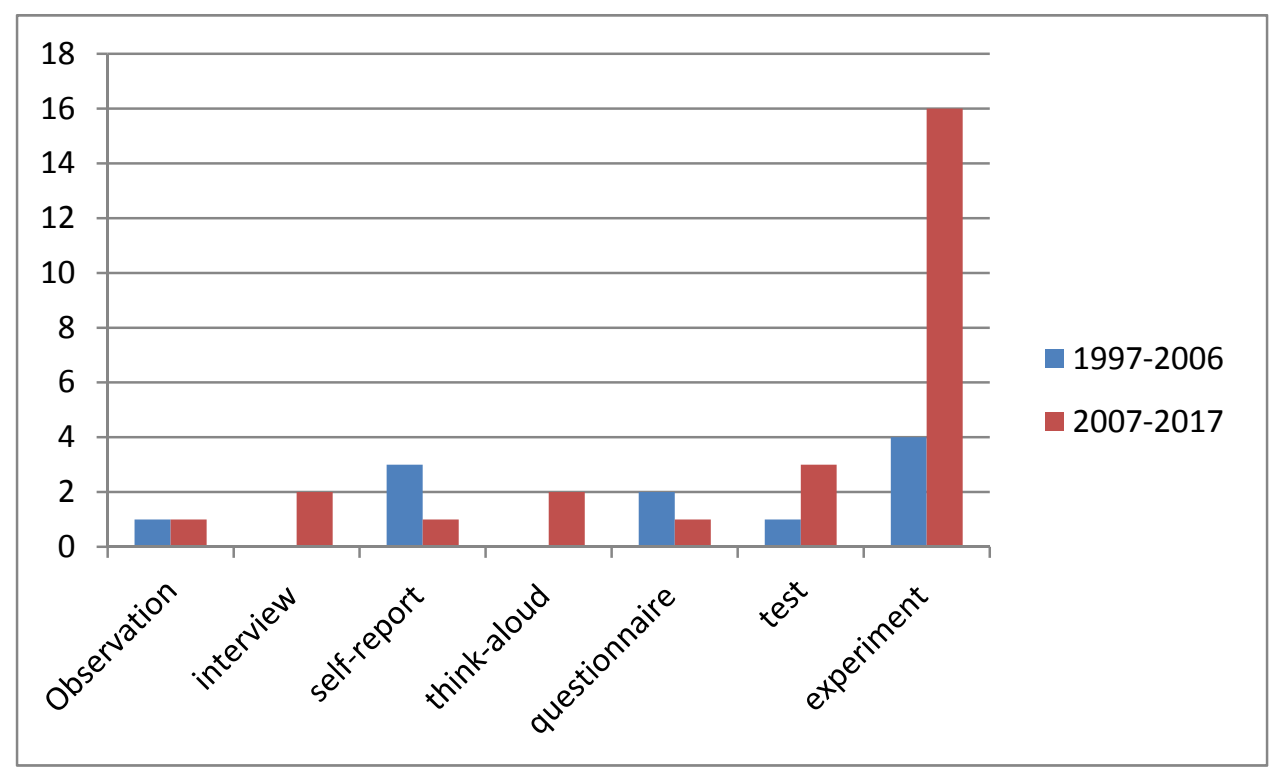

Figure 2. Comparison of data collection methods in different stages

There is another finding for the application of methods in data collection. In recent years, researchers preferred to adopt more than two methods to collect data in a single study. This tendency for methodological tri-angulations makes the process of data collection more valid and convincing, since dictionary use process is complex and a combination of different methods can be more revealing.

\subsection{Data Analysis Method}

When numerical data are involved, there are two statistic methods for data analysis: descriptive statistics and inferential statistics. Inferential statistics cover both parameter test and non-parameter test. The data analysis methods used in previous dictionary use empirical studies were summarized in Table 4 and Figure 3. It shows that i). as a basis for inferential statistics, descriptive statistics was adopted and presented in most studies (5 out of 9) in the period of 1997-2006. For the period of 2007-2017, six studies presented the descriptive statistics. As a pre-condition for further inferential statistics, descriptive statistics was necessary although it was not presented in the related studies; ii) as far as inferential statistics is concerned, most studies in the more recent period (2007-2017) adopted parameter test, and among them ANOVA was the most popular method for data analysis. When compared with the non-parameter test, parameter test is more sensitive to the differences among groups and is more revealing when dictionary use effectiveness or process is concerned in the studies. 
Table 4. Distribution of different statistic methods for data analysis

\begin{tabular}{lllllll}
\hline & Descriptive & Inferential & & Non-parameter \\
\cline { 2 - 7 } & percentage & LMM & ANOVA & $\begin{array}{l}\mathrm{t} \text {-test/ } \\
\mathrm{z} \text { test }\end{array}$ & correlation & Chi-square test \\
\hline $1997-2006$ & 5 & 0 & 3 & 1 & 0 & 0 \\
$2007-2017$ & 6 & 1 & 11 & 3 & 1 & 2 \\
\hline
\end{tabular}

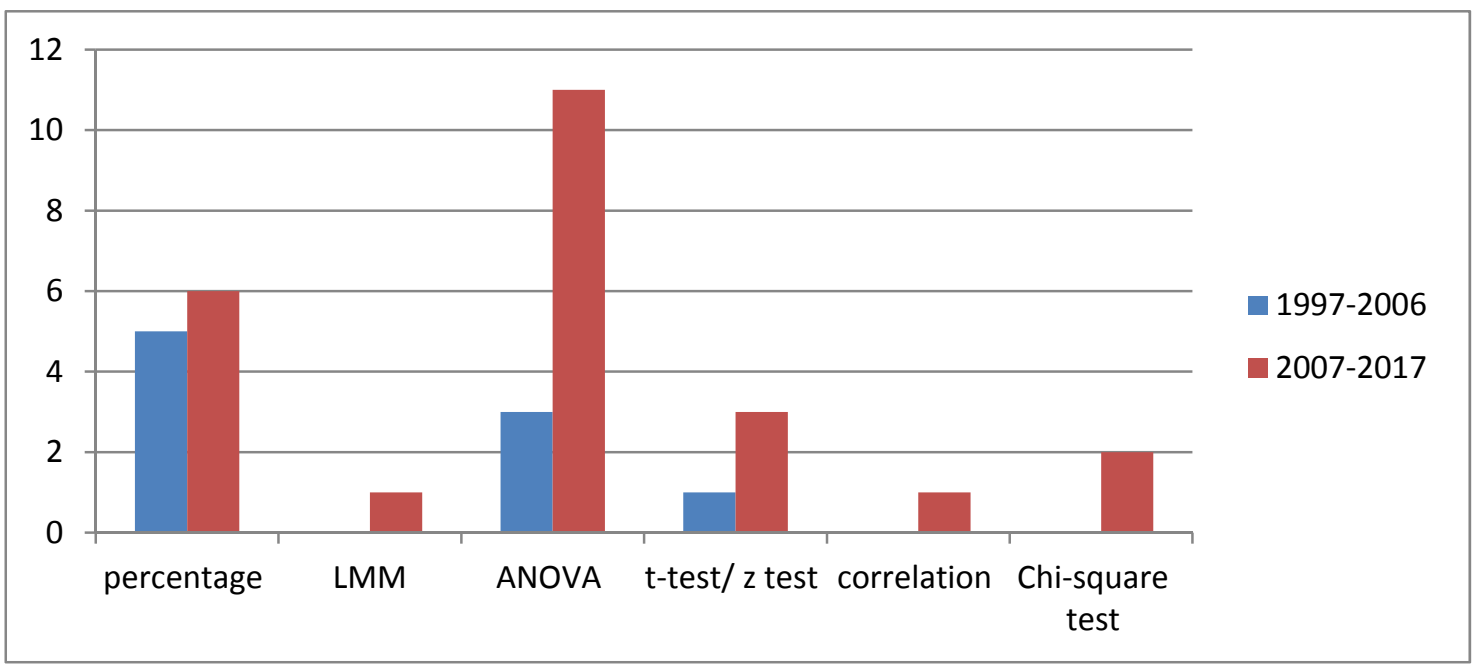

Figure 3. Comparison of data analysis methods in different periods

\subsection{Summary of the Findings}

Recent three decades witnessed the rapid development of dictionary use. Based on the analysis of the existing dictionary use studies published in International Journal of Lexicography, the following findings have been revealed in terms of research focus, methods for data collection and methods for data analysis.

a. There are great changes about research focus in different periods. While some hot topics (e.g., the effectiveness of dictionary use or of certain dictionary information) have remained popular over the past two decades, some topics, e.g., the exploration of dictionary using process, the effectiveness of e-dictionary/online dictionary, have received an increasing attention, but some others, e.g., the investigation on habits and needs of dictionary use have witnessed a decrease of interest recently.

b. Methods for data collection in dictionary use studies underwent a big change as well, shifting from the pure application of questionnaire to methods triangulation, including the simultaneous use of test/experiment and questionnaire/interview. Most of the studies tend to adopt more direct and controlled methods. In a single study, multiple methods for data collection were used. Data collected from different channels prove to be more revealing and make the results and findings more reliable.

c. As compared with the initial stage of dictionary use research, the recent decade sees an increase in the adoption of inferential statistics, especially the parameter test (e.g., ANOVA and t-test). The involvement of more complicated statistics accords with the development of research methods in applied linguistics and lexicography.

\section{Conclusion}

Dictionary use, as a crucial learning activity, involves a range of different factors, and the fundamental three factors are the goal of dictionary use (why users need to consult a dictionary), dictionary use process (how they consult a dictionary), and the effectiveness of dictionary use (what is the effect of the dictionary use) (Nesi, 2000). The present paper examined the existing studies on the following three corresponding elements: research focus, data collection methods and data analysis methods. They are shaped by each other. The specific focus of a single study determines the adoption of a particular method for data collection; and in turn how data are collected influences how they will be analyzed.

Once research on dictionary use is counted as a branch of science, Cohen and Manion's (1994) sequence of 
stages through which a science normally passes can be adopted to identify the development of the research. Cohen and Manion (1994) set out the sequences as follows:

I. Definition of the science and identification of the phenomena;

II. Observation stage: to identify and label the relevant factors or variables, and to develop categories and taxonomies;

III. Correlational research: variables and parameters are related to one another and information is integrated as theories begin to develop;

IV. Moving from correlation to causality: to systematically manipulate variables to see if experiments will produce expected results;

V. The establishment of a body of theory as the outcomes of the earlier stages is accumulated.

VI. The use of the established theory to resolve problems or as a source for further hypotheses.

According to the above sequence, until the end of the 1980s, research on dictionary use fell into the second stage (Tono, 2001). Surveys and case studies were adopted as the primary methods. In the 1990s, the growing interest in vocabulary learning gave rise to more empirical studies into the effect of dictionary use on vocabulary learning, most of which belongs to the stage III or IV.

In the early 2000s, the popularity of task-based language teaching attracted more attention to the use of dictionary in different types of tasks. This leads to a progress into stage IV, at which researchers manipulated variables to explore causality in an experiment setting. In a more recent decade, dictionary use research was influenced greatly by the development of other fields in applied linguistics, such as psycholinguistics and second language acquisition. It is possible for researchers to explore the use of a dictionary from more direct perspective by means of more advanced psychological experiment technologies. As such, we witnessed the occurrence of studies which adopted more directed methods for data collection, such as eye-tracking and E-prime. It is certain that the approach toward research on dictionary use become more and more scientific.

In brief, the development tendency for future studies of dictionary use can be outlined as follows:

a. The focus of dictionary use research tends to be more task-concerned than ever before. Specifically, more and more studies will take place in a language learning task setting which makes the design of future studies to be replicable and the results of those studies to be of practical value for language learning and pedagogical lexicography.

b. Influenced by the methodological progress in some related fields of applied linguistics, such as language teaching, second language acquisition and psycholinguistics, dictionary use researchers managed to improve the methodological standard to a higher level, including the use of psycholinguistic methods for data collection, the scientific design of experiment or quasi-experiment etc.

c. In response to the advancement of data collection methods, future studies prefer inferential statistics for data analysis, including both parameter and non-parameter tests. This makes research results more revealing and convincing.

It is expected that future dictionary use research, with a combined interest in both lexicography and language learning, would provide more scientific results and offer valuable suggestions for both fields.

\section{References}

Atkins, B. T., \& Varantola, K. (1998). Language learners using dictionaries: The final report on the EURLEX/AILA research project on dictionary use. In B. T. Atkins (Ed.), Using dictionaries: Studies of dictionary use by language learners and translators (pp. 21-81). Tübingen: Max Niemeyer. https://doi.org/10.1515/9783110929997

Béjoint, H. (1994). Tradition and Innovation in Modern English Dictionaries. Oxford: Clarendon Press.

Cohen, L., \& Manion, L. (1994). Research Methods in Education. London and New York: Routledge.

Dziemianko, A. (2010). Paper or Electronic? The Role of Dictionary Form in Language Reception, Production and the Retention of Meaning and Collocations. International Journal of Lexicography, 23(3), 257-273. https://doi.org/10.1093/ijl/ecp040

Hartmann, R. R. K. (1983). The bilingual learner's dictionary and its uses. Multilingua, 2, 195-201. https://doi.org/10.1515/mult.1983.2.4.195

Hartmann, R. R. K. (1987). Four perspectives on dictionary use: a critical review of research methods. In A. P. 
Cowie (Ed.), The Dictionary and the Language Learner (Lexicographica Series Maior 17, pp. 11-28). Tiibingen: Max Niemeyer Verlag.

He, J. N., \& Zhang, W. Z. (2009). State Analysis on the Empirical Data Collection Methods and Statistical Methods in Dictionary Use by Chinese EFL Learners. Modern Foreign Language, 32(1), 94-101.

Lew, R. (2016). Can a Dictionary Help you Write Better? A User Study of an Active Bilingual Dictionary for Polish Learners of English. International Journal of Lexicography, 29(3), 353-366. https://doi.org/10.1093/ijl/ecw024

Lew, R., Kazomierczak, R., Tomczak, E., \& Leszkowicz, M. (2018). Competition of Definition and Pictorial Illustration for Dictionary Users' Attention: An Eye-tracking Study. International Journal of Lexicography, 31(1), 53-77. https://doi.org/10.1093/ijl/ecx002

McCreary, D. R., \& Dolezal, F. (1998). Language learners and dictionary users: bibliographic findings and commentary. In T. Fontenelle et al. (Eds.), ACTESEURALEX'98 Proceedings (pp. 611-618, 2 vols). Papers Submitted to the Eighth EURALEX International Congress on Lexicography in Liège, Belgium. University of Liège, English and Dutch Departments.

Nesi, H. (2000). The Use and Abuse of EFL Dictionaries. Max Niemeyer Verlag Tübingen. https://doi.org/10.1515/9783110946031

Nesi, H. (2014). Research Timeline: Dictionary Use by English Language Learners. Language Teaching, 47(1), 38-55. https://doi.org/10.1017/S0261444813000402

Nurmukhamedov, U. (2017). The Contribution of Collocation Tools to Collocation Correction in Second Language Writing. International Journal of Lexicography, 30(4), 454-482. https://doi.org/10.1093/ijl/ecw031

Tono, Y. (2001). Research on Dictionary Use in the Context of Foreign Language Learning: Focus on Reading Comprehension. Tübingen: Max Niemeyer. https://doi.org/10.1515/9783110915013

Wiegand, H. E. (1998). Wörterbuchforschung. Untersuchungen zur Wörterbuchbenutzung, zur Theorie, Geschicte, Kritik und Automatisierung der Lexicographie. Berlin: Walter de Gruyter.

\section{Note}

This study was supported by the Research Funding for Social Science Original Program in Guangdong Universities (2016WTSCX027).

\section{Copyrights}

Copyright for this article is retained by the author, with first publication rights granted to the journal.

This is an open-access article distributed under the terms and conditions of the Creative Commons Attribution license (http://creativecommons.org/licenses/by/4.0/). 